\title{
Status of Scar in Repeat Cesarean Section in a Tertiary Hospital
}

\author{
Subha Shrestha, ${ }^{\text {a,d }}$ Raju Shakya, ${ }^{\mathrm{b}}$ Buddhi Kumar Shrestha, ${ }^{\mathrm{cdd}}$ Narinder Kaur, ${ }^{\mathrm{a}, \mathrm{d}}$ \\ Babita Thapa ${ }^{\mathrm{a}, \mathrm{d}}$
}

\begin{abstract}
:
Introduction: In modern Obstetrics, with rising trends of primary cesarean section (CS) for fetal and maternal interests, pregnancy over the scarred uterus is a challenge to all treating obstetricians. Despite the method of suturing of the cesarean scar, its fate in next pregnancy is still not measurable. Objective of this study was to evaluate the status of previous cesarean scar during repeat cesarean section (RCS) and calculate the maternal morbidity in those cases in a tertiary hospital. Methods: It was a descriptive, retrospective study conducted at department of Obstetrics of Lumbini Medical College Teaching Hospital. The study was conducted from $15^{\text {th }}$ July 2014 to $14^{\text {th }}$ July 2015 . The data were retrieved from the department of Medical Records. Women undergoing RCS were enrolled. The status of scar was evaluated in terms of intact scar, scar rupture, scar dehiscence, thin lower uterine segment, scar placenta previa, and adhesions as indicator of scar integrity. Results: There were 534 (25.4\%) CS among 2,098 deliveries during the study period. Ninety one (17.04\%) of them were RCS. Elective RCS were 73.6\% ( $n=67)$, and emergency RCS were $26.4 \%(n=24)$. Eighty two $(90.1 \%)$ women had RCS once and nine $(9.9 \%)$ had RCS for second time. Scar was intact in 22 (91.6\%), scar dehiscence in one (8.3\%), scar with adhesions in one (8.3\%) among emergency RCS and intact in $53(91.3 \%)$ and scar with adhesions in five (8.7\%) among elective RCS. There was no scar dehiscence and no scar rupture in two RCS women. Adhesions were documented twice higher in women whose primary CS was undertaken outside our hospital. Placenta previa and placenta accreta each were found in two cases. Conclusion: Most of the scars of repeat cesarean section were healthy with no scar rupture. We can consider trial of labor for scarred uterus with strict vigilance and in need, CS is always an option.
\end{abstract}

Keywords: maternal mortality • repeat cesarean section • uterine rupture

\section{INTRODUCTION:}

Along with rising trends of primary cesarean section (CS) from $5-7 \%$ in 1970 to $25-30 \%$ in 2003 , the rate of pregnancy over the scarred uterus is also ascending up. ${ }^{1}$ A century ago, Edward B. Craginoft

a - Lecturer

b - Consultant Family Physician, Lumbini Medical College

c - Assistant Professor

d - Department of Obstetrics and Gynecology

Lumbini Medical College Teaching Hospital, Palpa, Nepal

Corresponding Author:

Dr. Subha Shrestha

e-mail: subha_sht@hotmail.com

How to cite this article:

Shrestha S, Shakya R, Shrestha BK, Kaur N, Thapa B. Status of scar in repeat cesarean section in a tertiary hospital. Journal of Lumbini Medical College. 2016;4(1):42-5. doi: 10.22502/jlmc.v4i1.84. quoted dictum 'once cesarean, always cesarean' was justifiable for classical uterine incision. ${ }^{2}$ With invent of Kerr low transverse incision, it has been revised and trial of labor after cesarean has outbursten on practice as vaginal birth after cesarean (VBAC). When Repeat cesarean section has no alternatives i.e. recurrent causes for cesarean, unmet criteria for VBAC, failure VBAC, prior more than one repeat section, a parturient has to pass through hanging bridge. Due to unsettled issues on mode of delivery among women with prior CS, we have not advanced from Flamm dictum 'once cesarean, always a controversy' for past two decades. ${ }^{3}$

In Asian countries like ours, the decision making for mode of delivery depends on how we, obstetricians, counsel the client rather than on demand, 
medico-legal issue, or health insurance concern unlike in developed countries. Repeat Cesarean section (RCS) rate is higher despite explaining the option and benefits of VBAC in suitable candidates. It is due to various factors like, lady attending the hospital as unbooked case, dilemma on decision making, and fear of harm to baby and self from subjective part apart from contraindication to trial of labor after cesarean (TOLAC). Obstetricians fear for maternal morbidity and mortality as well as perinatal morbidity and mortality due to limited methods to judge the fetal jeopardy, and proven known risks secondary to delay in decision making like scar rupture, scar dehiscence, tear extensions, atonicity, postpartum hemorrhage, need for blood transfusion, cesarean hysterectomy, etc. 4,5,6,7,8

It is utmost important to judge the scar integrity by evaluating previous operative details and excluding factors predisposing potentially weak scar formation in subsequent repeat pregnancy. ${ }^{9,10}$ So, we have conducted this study to evaluate the scar integrity and its status during present repeat cesarean and to rate the maternal morbidity secondary to RCS.

\section{METHODS:}

This retrospective, observational study was conducted at department of Obstetrics of Lumbini Medical College Teaching Hospital, Nepal. Ninety one women undergoing repeat sesarean section (RCS) from $15^{\text {th }}$ July 2014 to $14^{\text {th }}$ July 2015 were enrolled.

Women who had undergone abdominal or pelvic surgeries and uterine surgeries in addition to cesarean section (CS) were excluded. Women who had documented co-morbidities likely to complicate present pregnancy e.g. idiopathic thrombocytopenic purpura, bleeding disorders, genital and abdominal tuberculosis, connective tissue disorders, malignancy etc. were also excluded.

Medical records were retrieved from Medical record section and required information were collected and plotted in the master chart. The status of scar was evaluated in terms of intact scar, scar rupture, scar dehiscence, thin lower uterine segment, scar placenta previa, adhesions (bladder, obscuring field of vision during surgery, etc) as indicator of scar integrity.

\section{RESULTS:}

There were total 534 cesarean section (CS) including 91 repeat cesarean section (RCS) out of 2,098 deliveries during the study period. Eighty two (90\%) had first RCS and nine (10\%) had second RCS. There were 67 (73.6\%) elective RCS and 24 (26.4\%) emergency RCS.

Mean age of the women was $26.4 \mathrm{yr}(S D=4.37)$ with most of them $(n=78,85.7 \%)$ belonging to 20 30 years age-group. Most women ( $n=56,68.2 \%)$ of first RCS were between 37-40 weeks of gestation. Among women with two RCS, seven (77.8\%) were between $37-40$ weeks of gestation and one $(11.1 \%)$ were $<36$ weeks and $>40$ weeks of gestation each.

All of the women had prior lower segment cesarean section (LSCS). There were intact scar in 22 (91.6\%), scar dehiscence in one (8.3\%), and scar with adhesions in one (8.3\%) among emergency RCS. There were $53(91.3 \%)$ intact scar and five (8.7\%) scar adhesions among elective RCS. The lower uterine segment was well formed in 13 (54.2\%), moderately formed in one (4.1\%), thinned out in eight (33.4\%) women. Three $(12.5 \%)$ women had placenta previa over previous scar who had emergency RCS. Among nine women who had two RCS, three (37.5\%) had thin scar, five $(62.5 \%)$ had well formed scar, seven (87.5\%) had intact scar, and one (12.5\%) had adhesions among elective RCS group. There was one intact scar, no scar dehiscence, and no scar rupture in women with two repeat CS. Adhesions were documented twice higher in women whose primary CS was undertaken outside $(n=49)$ compared to that inside our hospital $(n=33)$ in first RCS (i.e. 15 (30.6\%) versus seven (21.2\%)).

In our study, prior cesarean section was performed with various indications. Among them, fetal distress and primigravida with breech presentation accounted for 21 (25.6\%) and 14 (17\%) cases respectively, followed by non-progress of labor ( $n=8,9.7 \%)$, feto-pelvic disproportion $(n=7,8.5 \%)$, oligohydamnios ( $n=7,8.5 \%)$, failed induction $(n=6$, $7.3 \%)$, malpresentation other than breech $(n=5,6 \%)$, and bad obstetric history $(\mathrm{BOH})$, pregnancy induced hypertension $(\mathrm{PIH})$, and multiple gestation each $<5 \%$ among one RCS. Indications of second repeat section were fetal distress and non-progress of labor in two $(22.2 \%)$ cases each and BOH, PIH, and not in labor till 40 weeks in one (11.1\%) case each.

Indications for the present cesarean section were recurrent causes in $12(14.6 \%)$, not in labor 
in 15 (18.2\%), short spacing in nine (10.9\%), scar tenderness in six (7.3\%), fetal distress in six (7.3\%), failed VBAC in five $(6 \%)$, on request in six $(7.3 \%)$, oligohydramnios in four $(0.8 \%)$, malpresentation in six $(7.3 \%), \mathrm{BOH}$ in eight $(9.7 \%)$, IUGR in two $(2.4 \%), \mathrm{PIH}$ in one $(1.2 \%)$, obstructed labor in one (1.2\%), polyhydramnios in one (1.25) in one RCS group. In previous two CS women, eight (88.8\%) had elective repeat CS and one (11.2\%) had RCS in labor.

The maternal morbidity variables encountered in our study were post partum hemorrhage $(\mathrm{PPH})$ in seven $(8.5 \%)$, placenta previa over previous scar in three $(3.6 \%)$, blood transfusion in seven $(8.5 \%)$, APH in one $(1.2 \%)$, wound gap in one $(1.2 \%)$, hematuric urine in three (3.6\%) among first RCS women. Placenta accreta was encountered in one women who had PPH and needed blood transfusion. Hematuria was seen in women who had emergency RCS and had adhesions of bladder over lower uterine segment. Pregnancy with anemia was encountered in 28 (34.1\%) women with first RCS and in four (44.4\%) women with second RCS. Placenta accreta was diagnosed intra-operatively in a woman who had second RCS and she also had primary PPH needing blood transfusion. Eight women needed blood transfusion due to postpartum hemorrhage.

\section{DISCUSSION:}

In our study, the rate of repeat cesarean section (RCS) was $17.04 \%$ among 534 cesarean sections. Primary cesarean section rate is rising, so is the rate of repeat cesarean following. ${ }^{2}$ The study done in Nobel Medical College of Biratnagar by Subedi S. among 2011 women resulted 21.2\% rate of CS for previous CS. ${ }^{4}$ Enkin et al found 20.1\% of repeat CS in a study of 8899 women, which is similar to our study. ${ }^{11}$

The common indications of repeat CS in our study were 'not in labor' till 40 weeks ( $n=15,18.2 \%)$, recurrent cause where VBAC is contraindicated in 14.6\%, fetal distress 7.3\%, Malpresentation 7.3\% among others. This is similar to the study of Karim F. et al. in 778 women where fetal distress were $8.3 \%$, malpresentation 5.8\%, PIH 3.4\%, breech presentation $10 \%$, and oligohydramnios $14 \%{ }^{12}$

There is increased risk of uterine rupture, intra-operative bleeding, and higher maternal morbidity with high order cesarean section, specially where the cases are unbooked and land up in emergency with previous recurrent cause for CS. ${ }^{13}$ We took all previous two repeat cesarean women to RCS (eight elective and one emergency) because they were unbooked case, with history of prior CS in periphery and no definite documentation of previous surgery and indication.

The maternal morbidity included hemorrhage $(8.5 \%)$, blood transfusion $(7.3 \%)$, hematuria $(3.6 \%)$, wound gap (1.2\%), scar placenta previa (3.6\%), scar dehiscence $(1.2 \%)$ in first repeat CS. Placenta accreta resulted in one women of second repeat CS. These results are similar to the study done by Mafatlal SJ. and co-workers at Gujarat among 385 women, and Nargis N. et al. among 570 women at Dhaka. ${ }^{14,15}$ In our study, RCS was done in six women where no scar dehiscence or rupture was noted similar to the study from Ludhiana, India by Puri P. and co-workers. ${ }^{16}$ There was high risk of morbidly adherent placenta in women with low lying placenta and previous section, so planned antepartum and intrapartum assessment is mandatory to prevent maternal mortality and morbidity. The preparedness for blood transfusion and management of antecedent complications has to be considered beforehand..$^{9,10}$

In a pregnant woman with two past caesarean sections, elective RCS is indicated in a weak scar, a recurrent indication, an obstetric complication in the current pregnancy, or a scenario where a safe vaginal delivery is not feasible. ${ }^{17}$

\section{CONCLUSION:}

Most of the scar of pregnant women undergoing repeat cesarean section were healthy. We can offer them a trial of labor with strict vigilance and a readily available backup facility of cesarean section.

\section{Conflict of Interest: None Declared.}

Fund available: None.

\section{REFERENCES:}

1. Christilaw JE. Cesarean section by choice: Constructing a reproductive rights framework for the debate. Int J Gynecol Obstet. 2006;94:262-8.

2. Cragin EB. Conservatism in obstetrics. NY Med J. 1916;104:1-3. 
3. Williams JW. Prior Cesarean Delivery. $24^{\text {th }}$ ed. Cunningham FG, Leveno KJ, Bloom SL, Spong CY, Dashe JS, Hoffman $\mathrm{BL}$, et al., editors. Williams Obstetrics. USA: McGraw Hill companies; 2014. 609-21 p.

4. Subedi S. Rising rate of cesarean section- A year review. Journal of Nobel college. 2012;1(2):72-6.

5. McMahon MJ, Luther ER, Bowes WA Jr, Olshan AF. Comparison of trial of labor with and elective second cesarean section. N Eng J med. 1996 sep;335(10):689-95.

6. Mansoor M. To study uterine rupture and fetal distress in patients with previous LSCS. Pak J MHS. 2010 AprJun;4(2):105-8.

7. Shamshad. Factors leading to increased cesarean section rate. Gomal J med Sci. 2008 Jan-Jun;6(1):1-5.

8. Krishna U, Daftary S. Induction of labor. $5^{\text {th }}$ ed. Krishna U, Shah D, Salvi V, editors. Pregnancy at risk: A Practical approach to high risk pregnancy and delivery. The federation of Obstetric and Gynecological Societies of India. Jaypee brothers publication; 2010.581 p.

9. Dewhurst J. Obstetrics Emergencies. $8^{\text {th }}$ ed. Edmonds K, editor. Dewhurst's Textbook of Obstetrics and Gynecology. UK: Wiley \& Blackwell; 2012. 300 p.

10. Paterson-Brown S, Singh C. Developing a care bundle for the management of suspected placenta accreta. Obstet and
Gynecol. 2010;12:21-27.

11. Enkin M. labour and delivery following previous cesarean section. Edkin M, Keirs MJ, Chalmers I, editors. Elective care in pregnancy and childbirth. Oxford: oxford university press, 1989. 1196-1215 $\mathrm{p}$.

12. Karim F, Ghazi A, Ali T, Aslam R, Afreen U, Farhat R. Trends and determinants of Cesarean section. J Surg Pak. 2011 Jan-Mar;16(1):22-7.

13. Birth after Previous cesarean birth. Green-top guideline no.45. RCOG. 2015 oct. 2-31 p.

14. Mafatlal SJ, Narendrabhai MM. Analysis of mode of delivery in women with previous one cesarean section. J Obstet Gynecol India. 2009 Mar-Apr;59(2):136-9.

15. Nargis N, Al-Mahmood AK, Akhter D. Evaluation of uterine scar on repeat second cesarean section in patients with previous cesarean section. AKMMC J. 2012;3(1):16-9.

16. Puri $\mathrm{P}$, Abraham $M$, Grover S. Vaginal birth after one previous lower segment cesarean section. J K sci. 2011octDec;13(4):179-81.

17. Wijesinghe PS, Ekanaake CD. Twice a cesarean, always a cesarean: fact or fiction? Sri-lanka J Obstet Gynecol. 2012; 34:131-34. 